\title{
Correction to: Non-communicable disease prevention policy process in five African countries
}

Pamela A. Juma ${ }^{1 *}$, Shukri F. Mohamed ${ }^{1}$, Beatrice L. Matanje Mwagomba ${ }^{2}$, Catherine Ndinda ${ }^{3}$, Clarisse Mapa-tassou ${ }^{4,5}$, Mojisola Oluwasanu ${ }^{5}$, Oladimeji Oladepo ${ }^{6}$, Opeyemi Abiona ${ }^{6}$, Misheck J. Nkhata ${ }^{7}$ Jennifer P. Wisdom ${ }^{8}$ and Jean-Claude Mbanya ${ }^{4,5}$

\section{Correction}

After publication of the article [1], it was noticed that the title has erroneously included 'authors' in the end. The correct title should be as follows which herewith has been corrected in this erratum:

Non-communicable disease prevention policy process in five African countries

We apologize for the inconvenience caused.

\section{Author details}

'African Population and Health Research Center, Nairobi, Kenya.

${ }^{2}$ LighthouseTrust, Lilongwe, Malawi. ${ }^{3}$ Human Science Research Council,

Pretoria, South Africa. ${ }^{4}$ African Regional Health Education Centre, Department of Health Promotion and Education, Yaoundé, Cameroon. ${ }^{5}$ Health of

Population in Transition Research Group (HoPiT), Yaoundé, Cameroon.

${ }^{6}$ Faculty of Public Health, University of Ibadan, Ibadan, Nigeria.

${ }^{7}$ Anthropology Department, Catholic University of Malawi, Blantyre, Malawi.

${ }^{8}$ Wisdom Consulting, New York, NY, USA.

Received: 27 August 2018 Accepted: 27 August 2018

Published online: 11 September 2018

\section{Reference}

1. Juma PA, et al. Non-communicable disease prevention policy process in five African countries. BMC Public Health. 2018;18(Suppl 1):961. https://doi.org/ 10.1186/s12889-018-5825-7

\footnotetext{
* Correspondence: atienopam@yahoo.com

${ }^{1}$ African Population and Health Research Center, Nairobi, Kenya
} 